\title{
长白山北坡植物群落组成、结构及物种 多样性的垂直分布
}

赵淑清 方精云 $^{1}$ 宗占江 ${ }^{2}$ 朱 彪 ${ }^{1}$ 沈海花 ${ }^{1}$

1 ( 北京大学环境学院生态学系, 北京大学生态学研究与教育中心 北京大学地表过程分析与模拟教育部重点实验室, 北京 100871 ) 2 (吉林省长白山国家级自然保护区管理局, 安图 133613)

摘要 : 通过沿海拔梯度的系统调查, 运用 TWINSPAN 分类方法, 划分出长白山北坡的主要植物群落类型, 对这些群 落的组成和结构进行了分析。利用物种丰富度、 $\alpha$ 多样性和 $\beta$ 多样性等指标, 研究了群落多样性随海拔梯度的变 化趋势。结果表明, 乔木层植物可分为 4 个群落类型 : 从低海拔到高海拔依次为红松 (Pinus koraiensis) 针阔混交 林、红松针阔叶树种与云冷杉组成的过渡群落、云冷杉暗针叶林以及岳桦林 (Betula ermanii)。乔木层优势种重要 值的分析清楚地反映出长白山北坡植被垂直带谱的优势成分。径级频度分布的分析表明该区域主要群落的自我 更新状况良好。植物物种多样性随海拔梯度的变化趋势为: 随海拔升高, 乔木层和灌木层的物种丰富度呈下降趋 势, 但草本层的变化趋势不明显; 乔木层和灌木层的 $\alpha$ 多样性 (Shannon-Wiener 指数) 呈下降趋势, 草本层则变化 不明显; 无论是木本层还是草本层的 Pielou 均匀度指数均没有明显的变化; 乔木层、灌木层和草本层植物的 $\beta$ 多 样性 (Cody 指数) 均随着海拔的升高而下降。

关键词：群落分类，群落结构，海拔梯度，物种丰富度， $\alpha$ 多样性， $\beta$ 多样性

中图分类号：Q948 文献标识码 : A 文章编号 : 1005-0094(2004)01-0164-10

\section{Composition, structure and species diversity of plant communities along an altitudinal gradient on the northern slope of Mt. Changbai , Northeast China}

ZHAO Shu-Qing $^{1}$, FANG Jing-Yun ${ }^{1}$, ZONG Zhan-Jiang $^{2}$, ZHU Biao ${ }^{1}$, SHEN Hai-Hua ${ }^{1}$

1 Department of Ecology, College of Environmental Sciences , Center for Ecological Research \& Education , and Key Laboratory for Earth Surface Processes of the Ministry of Education, Peking University , Beijing 100871

2 Administrative Bureau of National Nature Reserve of Mt. Changbai , Jilin Province ,Antu 133613

Abstract : The patterns of biodiversity along altitudinal gradients are well-documented ecological phenomena. Community composition and structure are important factors affecting diversity patterns in plant communities. Furthermore, species diversity along altitudinal gradient differs in different layers at different scales. In this paper, we analyzed the composition and structure of communities on the northern slope of Mt. Changbai based on TWINSPAN classification. The patterns of plant diversity for tree, shrub and herb layers were described by indices of species richness , $\alpha$ diversity and $\beta$ diversity. Four community groups characterized by different dominants in the tree layer were distinguished : (1) mixed coniferous and broad-leaved forests (700 - $1065 \mathrm{~m}$ a. s. l. ) dominated by Pinus koraiensis, Tilia amurensis , Fraxinus mandschurica , and Acer mono, including secondary birch forest ( $1150 \mathrm{~m} \mathrm{a.} \mathrm{s.} \mathrm{1)} \mathrm{dominated} \mathrm{by} \mathrm{Betula}$ platyphylla, which developed from natural pine and deciduous forests due to disturbance ; (2) transitional forests of mixed coniferous and broad-leaved forest and sub-alpine coniferous forests $(1100-1300 \mathrm{~m}$ a. s. l. ) ; (3) sub-alpine coniferous forests ( 1300 - $1780 \mathrm{~m}$ a. s. l. ) dominated by Picea jezoensis ,Abies nephrolepi and Larix olgensis ; and (4) alpine birch forests (1800 - $2000 \mathrm{~m}$ a. s. 1. ) dominated by Betula 
ermanii. Distribution of importance values of dominants explicitly indicated a vertical pattern of these four forest types. Frequency distribution of DBH classes suggested major forest types in Mt. Changbai were regenerating at a healthy pace. Species richness in the tree and shrub layers declined with altitude, while herb layer species richness showed no significant trend along the altitudinal gradient. With increasing altitude , $\alpha$ diversity , represented by the Shannon-Wiener index , decreased for both tree and shrub layers with no clear trend for herb layer. Pielou evenness index in the three layers showed no noticeable change with increasing altitude. $\beta$ diversity, indicated by the Cody index , declined with increasing altitude for all three layers.

Key words : $\alpha$ diversity, altitudinal gradient , $\beta$ diversity , community classification , community structure , species richness

山地由于其复杂多样的生态环境条件,成为多 种生物物种生存、繁衍和保存下来的种质库, , 物多样性的研究历来为生态学家所关注 (Whittaker ,1956, 1967, 1975; Beals , 1969 ; Hamilton \& Perrott , 1981 ; Odland \& Birks , 1999 ; Dolezal \& Srutek , 2002 )。海拔影响山地物种分布的非生物条件如气 候和土壤等, 因此, 是影响山地物种组成和群落结构 的重要因素 (Whittaker, 1975 ; Austin ,1980;Austin et al. , 1996 ; Austrheim , 2002)。尽管物种多样性 随海拔升高而逐渐减少被认为是山地物种多样性垂 直变化的一种普遍格局 (Brown, 1988 ; Begon et al. , 1996) ,但也有研究表明，中海拔地区拥有最高 的物种多样性，即随海拔的升高，物种多样性先增加 后减少（McCoy，1990；Rahbek，1997；王国宏， 2002 )。也就是说，物种多样性的垂直格局在不同 的山体有不同的反映。因此, 有必要对自然界各种 重要山地的生物多样性进行案例研究, 以便为阐明 山地生物多样性的格局积累基础资料。

吉林长白山是东亚大陆在我国境内唯一具有高 山冻原的山地, 也是东北植物区系唯一拥有明显植 被垂直带谱的山脉。独特的地理位置使长白山成为 温带山地植物多样性垂直分布格局研究的理想场 所，有关长白山植物群落物种多样性的研究已有很 多报道 (王战等 , 1980 ; Šrutek \& Lepš , 1994 ; Liu， 1997 ; 郝占庆等 ,2001；2002；Deng et al. ,2001)。

本文作为我国山地物种多样性系列研究的组成 部分,从物种多样性以及对其产生影响的群落组成 和结构方面对长白山北坡的植物群落进行了研究, 试图对以往的工作作一些补充。

\section{1 研究区概况与研究方法}

\section{1 研究区概况}

长白山 $\left(41^{\circ} 23^{\prime}-42^{\circ} 36^{\prime} \mathrm{N}, 126^{\circ} 55^{\prime}-129^{\circ} \mathrm{E}\right)$ 位于我国吉林省的东南部, 与朝鲜相邻, 是欧亚大陆 东岸的最高山, 海拔 $2744 \mathrm{~m}$ 。它东边受太平洋影 响，气候潮湿多雨，从山脚到山顶，年降水量变幅在 $800-1800 \mathrm{~mm}$ 之间，年相对湿度为 $65 \%-74 \%$,年 均温度在 - 7.3-4.9 ${ }^{\circ} \mathrm{C}$ 之间 (张凤山等, 1980)。 生态气候图 (图 1) 直观地显示了长白山山脚和山顶 的多年月平均温度和降水状况及山脚和山顶较大的 气候差异。山体下部和上部气候和土壤条件的巨大 差异, 使长白山的植被垂直带谱十分明显。在长白 山北坡, 从山脚到山顶依次为落叶阔叶林、红松针阔 混交林、亚高山针叶林、亚高山岳桦矮曲林和高山苔 原带 (王战等, 1980)。长白山北坡位于长白山人 与生物圈” 自然保护区的保护范围，因此这里的植 被保存相对完好, 是研究山地植物群落随海拔梯度 变化的良好场所。

\section{2 研究方法}

\subsection{1 样方调查}

于 2000 年 8 月对长白山北坡植物群落多样性进 行了调查。样地设置方法为 : 在 $700-2600 \mathrm{~m}$ 的海拔 范围内, 沿海拔梯度每间隔 $50-100 \mathrm{~m}$ 设置 1 个样 地, 共 32 个样地。乔木层样方大小为 $20 \mathrm{~m} \times 30 \mathrm{~m}$, 再 按照打格子的方法将其分成 6 个 $10 \mathrm{~m} \times 10 \mathrm{~m}$ 的小样 方。在其中选取一个 $10 \mathrm{~m} \times 10 \mathrm{~m}$ 的小样方作为灌木 层样方 进行灌木调查; 在每个乔木层样方中梅花取 样, 设置 5 个 $1 \mathrm{~m} \times 1 \mathrm{~m}$ 的草本层样方。乔木层中 对 $\mathrm{DBH}>4 \mathrm{~cm}$ 的所有个体 测定其树高和胸围 ; 在灌木 层和草本层的调查中，则记录每个物种的名称、多度 和高度。另外 对每个样地, 测其海拔、经纬度、坡向、 坡度和坡位, 并在每个植被带及每两个相邻植被带的 过渡带挖 1-2 个 $1 \mathrm{~m}$ 深的土壤剖面, 测定土壤的理 化性质。各样地的基本信息见表 1 。 


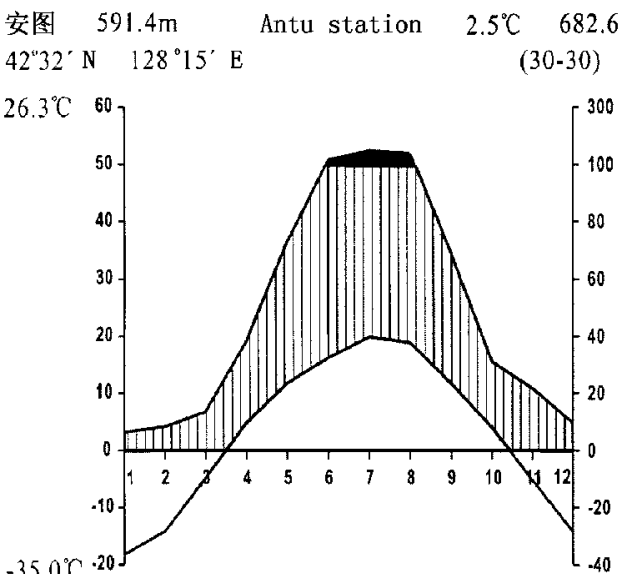

月份 Month
安图天池 $2623.0 \mathrm{~m}$ Tianchi station $-7.4^{\circ} \mathrm{C} \quad 1351.4 \mathrm{~mm}$ $42^{\circ} 01^{\prime} \mathrm{N} \quad 128^{\circ} 05^{\prime} \mathrm{E}$

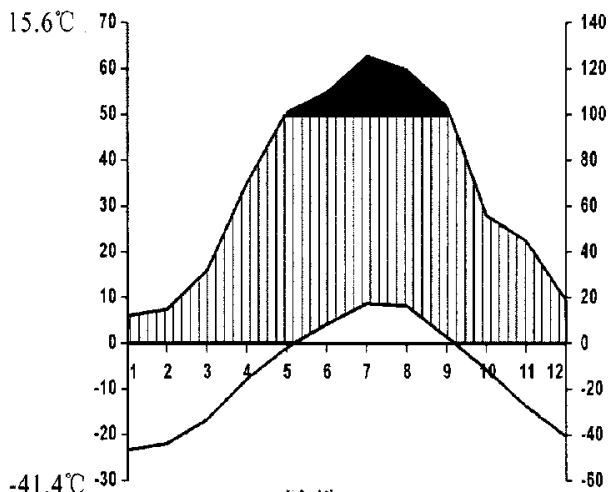

月份 Month

图 1 研究区生态气候图

Fig. 1 Climate diagrams of Mt. Changbai

表 1 调查样方基本信息

Table 1 Characteristics of the 32 plots

\begin{tabular}{|c|c|c|c|c|c|c|c|c|c|c|c|c|}
\hline \multirow{2}{*}{$\begin{array}{l}\text { 编号 } \\
\text { Plot } \\
\text { No. }\end{array}$} & \multirow{2}{*}{$\begin{array}{c}\text { 群落类型 } \\
\text { Community } \\
\text { type }\end{array}$} & \multirow{2}{*}{$\begin{array}{c}\text { 海拔 } \\
\text { Altitude } \\
(\mathrm{m})\end{array}$} & \multicolumn{6}{|c|}{$\begin{array}{c}\text { 乔木层 } \\
\text { Tree Layer }\end{array}$} & \multicolumn{2}{|c|}{$\begin{array}{c}\text { 灌木层 } \\
\text { Shrub Layer }\end{array}$} & \multicolumn{2}{|c|}{$\begin{array}{c}\text { 草本层 } \\
\text { Herb Layer }\end{array}$} \\
\hline & & & $\begin{array}{l}\text { 面积 } \\
\text { Area } \\
\left(\mathrm{m}^{2}\right)\end{array}$ & $\begin{array}{c}\text { 物种数 } \\
\text { No. of } \\
\text { species }(S)\end{array}$ & $\begin{array}{c}\text { 最大树高 } \\
H_{\max } \\
(\mathrm{m}) \\
\end{array}$ & $\begin{array}{c}\text { 最大胸径 } \\
\mathrm{DBH}_{\max } \\
(\mathrm{cm})\end{array}$ & $\begin{array}{c}\text { 胸高断面 } \\
\text { 积之和 BA } \\
\left(\mathrm{m}^{2} / \mathrm{hm}^{2}\right)\end{array}$ & $\begin{array}{c}\text { 立木密度 } \\
\text { N ( stems) } \\
\mathrm{hm}^{2} \text { ) }\end{array}$ & $\begin{array}{l}\text { 面积 } \\
\text { Area } \\
\left(\mathrm{m}^{2}\right)\end{array}$ & $\begin{array}{c}\text { 物种数 } \\
\text { No. of } \\
\text { species }(S)\end{array}$ & $\begin{array}{l}\text { 面积 } \\
\text { Area } \\
\left(\mathrm{m}^{2}\right)\end{array}$ & $\begin{array}{c}\text { 物种数 } \\
\text { No. of } \\
\text { species }(S)\end{array}$ \\
\hline 1 & $\square$ & 744 & 600 & 9 & 26.8 & 76.4 & 37.9 & 533 & 100 & 12 & 1 & 14 \\
\hline 2 & $\square$ & 781 & 600 & 12 & 24.5 & 51.9 & 30.4 & 1100 & 100 & 11 & 1 & 12 \\
\hline 5 & $\square$ & 1065 & 600 & 8 & 27 & 34.7 & 32.5 & 1267 & 100 & 14 & 1 & 11 \\
\hline 6 & $*$ & 1085 & 600 & 8 & 31 & 46.6 & 30.7 & 1367 & 100 & 11 & 1 & 15 \\
\hline 7 & $\square$ & 1150 & 600 & 7 & 27 & 34.4 & 35.4 & 2967 & 100 & 11 & 1 & 13 \\
\hline 8 & $*$ & 1202 & 600 & 9 & 31 & 58.9 & 42.8 & 1167 & 100 & 7 & 1 & 11 \\
\hline 9 & $*$ & 1272 & 600 & 11 & 27 & 43.6 & 42.5 & 1000 & 100 & 10 & 1 & 12 \\
\hline 10 & $\diamond$ & 1378 & 600 & 7 & 29 & 54.1 & 44.1 & 950 & 100 & 5 & 1 & 16 \\
\hline 15 & $\diamond$ & 1771 & 600 & 4 & 21.5 & 58.8 & 41.5 & 1467 & 100 & 3 & 1 & 13 \\
\hline 16 & 0 & 1819 & 600 & 2 & 15.6 & 44.6 & 28.2 & 917 & 100 & 5 & 1 & 11 \\
\hline 17 & 0 & 1825 & 600 & 3 & 19 & 43.6 & 28.2 & 1100 & 100 & 5 & 1 & 12 \\
\hline 18 & 0 & 1888 & 600 & 2 & 13.8 & 33.1 & 24.4 & 1350 & 100 & 3 & 1 & 9 \\
\hline 19 & 0 & 1920 & 600 & 1 & 15.8 & 57.4 & 49.3 & 1250 & 100 & 3 & 1 & 13 \\
\hline 20 & 0 & 1996 & 600 & 1 & 9.4 & 31 & 25.9 & 2233 & 100 & 3 & 1 & 9 \\
\hline 21 & $\Delta$ & 2030 & & & & & & & & & 1 & 16 \\
\hline 22 & $\Delta$ & 2087 & & & & & & & & & 1 & 15 \\
\hline 23 & $\Delta$ & 2089 & & & & & & & & & 1 & 6 \\
\hline 24 & $\Delta$ & 2147 & & & & & & & & & 1 & 10 \\
\hline 25 & $\Delta$ & 2218 & & & & & & & & & 1 & 10 \\
\hline
\end{tabular}




\subsection{2 重要值及多样性测度指标的计算}

某一物种在群落中的重要性用重要值 (IV) 来 表示。乔木层及灌木层、草本层的重要值计算方法 如下：

$$
\begin{aligned}
& \mathrm{IV}_{\text {乔 }}=\frac{\text { 某一树种的胸高断面积之和 }}{\text { 样方内所有树种胸高断面积之和 }} \\
& \mathrm{IV}_{\text {灌.草 }}=\frac{\text { 相对多度 }+ \text { 相对高度 }+ \text { 相对盖度 }}{3}
\end{aligned}
$$

以重要值作为物种的定量信息来计算 $\alpha$ 多样 性和 $\beta$ 多样性。

Shannon-Wiener 指数和 Pielou 均匀度指数表示 $\alpha$ 多样性; 用 Cody 指数来反映 $\beta$ 多样性。具体计 算方法如下：

Shannon-Wiener 指数 : $H^{\prime}=-\sum_{i=1}^{S} P_{i} \ln P_{i}$ ( Magurran , 1988)

Pielou 指数 : $E=H^{\prime} / \ln S$ ( Pielou, 1977)

其中 : $S$ 为样地中的物种数目,$P_{i}$ 为种 $i$ 的重要 值 ( IV)。

Cody 指数 : $\beta_{\mathrm{C}}=\frac{g(H)+l(H)}{2}=\frac{a+b-2 c}{2}$ ( Magurran , 1988)

式中 $a$ 和 $b$ 分别为两群落各自的物种数, $c$ 为 两群落的共有物种数 $g(H)$ 为沿海拔梯度 $H$ 增加的 物种数 $l(H)$ 为沿海拔梯度 $H$ 减少的物种数。

\subsection{3 乔木层的群落类型分类、组成和结构分析}

乔木层是森林生态系统的主要成分，其组成成 分决定了林下的灌木层和草本层的组成和结构。利 用乔木层样方的物种重要值矩阵信息，在 PCORD4. 0 的二元指示种分析 ( Two-way Indicator Species Analysis ,TWINSPAN) 模块下, 对长白山北坡乔 木层的植物群落进行聚类分析。另外, 对乔木层群 落的组成和结构也进行了分析。

\section{2 结果与分析}

\section{1 乔木层的物种组成和结构}

\subsection{1 主要植被类型}

TWINSPAN 群落分类结果将 20 个乔木层的植 物群落归并为 4 个植被类型 (图 2)。红松针阔混 交林分布在海拔 $700-1065 \mathrm{~m}$ 范围内，在这一植被 带内 红松占据上层林冠，与红松混交的树种有红皮 云杉 ( Picea koraiensis)、水曲柳 (Fraxinus mandshurica )、黄菠夢 (Phellodendron amurense)、胡桃楸

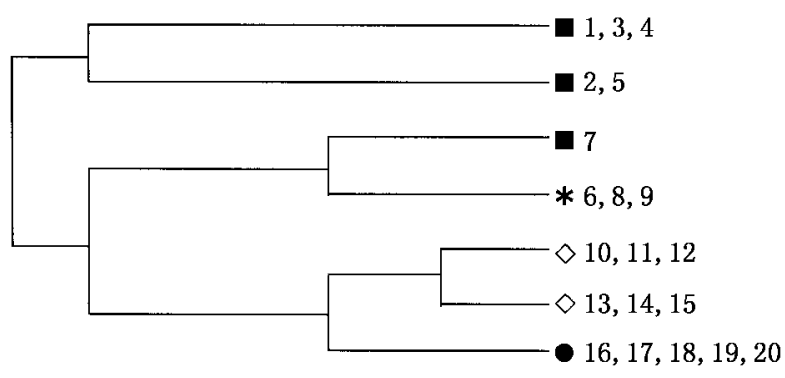

图 220 个乔木层样方的 TWINSPAN 群落分类结果 Fig. 2 Community groups for 20 tree plots by TWINSPAN classification

群落类型标识见表 1 Community type symbols as in Table. 1.

(Juglans mandshurica) 、械树（Acer spp.）、椴树 (Tilia spp.)、杨树 (Populus spp.)、榆树 (Ulmus spp. )、白桦 (Betula platyphylla)。乔木层通常分 2 -3 个亚层 故称之为 混交复层异龄林” (王战等, 1980 )。但在海拔 $1150 \mathrm{~m}$ 处出现一个白桦占优势的 群落类型, 它是原生红松针阔混交林受到火灾等干 扰后形成的次生植被。在白桦、山杨 (Populus davidiana) 等阳性阔叶树的蔽荫下，红松、云杉 (Picea spp. ) 等喜阴针叶树逐渐成长起来, 恢复成针阔混 交林，所以这种群落类型是过渡性次生的森林类型 (祝廷成,1999)。在样地实地调查中我们也发现红 松曾被砍伐的痕迹。

在 $1085-1272 \mathrm{~m}$ 海拔区间范围内分布的是红 松针阔叶树种与云冷杉组成的过渡群落, 该植物群 落类型既有红松和槭树、椴树、杨树等阔叶树成分， 也有鱼鳞云杉 (Picea jezoensis)、臭冷杉 (Abies nephrolepis) 和长白落叶松 (Larix olgensis) 等针叶树种， 物种组成相对丰富。

云冷杉暗针叶林主要分布于 $1378-1771 \mathrm{~m}$ 的 海拔区间范围内, 群落组成以鱼鳞云杉和臭冷杉占 优势。其中在 $1378-1545 \mathrm{~m}$ 和 $1619-1771 \mathrm{~m}$ 海拔 区间，上述优势针叶树种外的其他树种组成有些差 异：前者分布有槭树、杨树、枫桦(Betula costata)、 岳桦 (B. ermanii) 和花楸 (Sorbus pohuashanensis)； 而在后者仅分布有岳桦和花楸两种树种。

$1819-1996 \mathrm{~m}$ 海拔区间内分布的是岳桦纯林 或混生有 1-4 株花楸、臭冷杉或长白落叶松。岳桦 由于其较强的抗寒、抗风力而成为长白山森林分布 的上限树种。

\subsection{2 乔木物种组成和分布}


在长白山海拔 $744-1996 \mathrm{~m}$ 间 20 个乔木样方 内共记录到乔木树种 33 种隶属于 12 科 19 属。参 照 Vazquez \& Givnish (1998) 的分析方法, 在每个样 方内根据每个树种重要值的大小篮选出两个优势树 种, 共获得乔木样方的 12 个优势树种, 分别为花楸、 岳华、长白落叶松、白桦、青杨 (Populus ussuriensis)、 水冬瓜赤杨 (Alnus sibirica) 、臭冷杉、鱼鳞云杉、红 松、紫椴 (T. mandshurica)、水曲柳和蒙古栎 (Quercus mongolica)。这些优势种反映了地处温带北部 海洋性湿润气候条件下的长白山地区乔木树种组成 的特点, 比如亚高山矮曲林、地带性植被红松针阔混 交林的组分在这些优势树种中均有体现。

图 3A 和 B 分别给出了在某一海拔段作为最优 势种和次优势种至少出现一次的物种的重要值在海 拔梯度上的分布。从这些优势种重要值随海拔高度 的变化不难发现构成长白山北坡各垂直带谱植物群 落的优势成分。比如温带针阔混交林的典型阔叶树 种紫椴、水曲柳等主要分布在低海拔段 红松和白桦 也分布在低海拔地段，其中红松是该区域地带性植 被的成分, 而白桦是原生红松针阔混交林受到火灾 等干扰后形成的次生植被; 中海拔地段分布的主要
是臭冷杉、鱼鳞云杉和长白落叶松等针叶树种; 长 白落叶松分布的海拔最高, 其次是鱼鳞云杉和臭冷 杉; 岳华的分布范围相对较广, 从中海拔到高海拔 都有分布，但在高海拔占绝对优势。

\section{1 .3 径级分布}

乔木层树种的胸径分布是重要的群落结构特 征。从径级分布图 (图 4) 可以看出, 四种森林类型 的径级分布基本上都呈倒 J" 型, 即小径级的个体 数量居多; 随着胸径增大, 立木株数减少。表明这 些森林类型的天然更新状况良好。仔细分析不难发 现, 不同群落类型的径级分布有其自身的特点: 分 布在高海拔处的岳桦林群落,除了热量条件较好 (半阳坡) 的 19 号样地岳桦最大胸径为 $57.4 \mathrm{~cm}$ 外, 其余样地的乔木个体 DBH 均小于 $48 \mathrm{~cm}$ 。其他 三种群落的径级分布范围相对较宽, 如暗针叶林群 落的乔木个体最大胸径高达 $79.6 \mathrm{~cm}$ (Plot 13)。除 了受到干扰后形成的次生群落 (Plot 7 ) 的乔木个体 胸径较小外红松针阔混交林群落的径级分布范围 很宽, 最大胸径达到 $76.4 \mathrm{~cm}$ (Plot 1 ), 而其径级的 不连续分布在一定程度上也反映了该群落复层异龄 林的垂直结构。

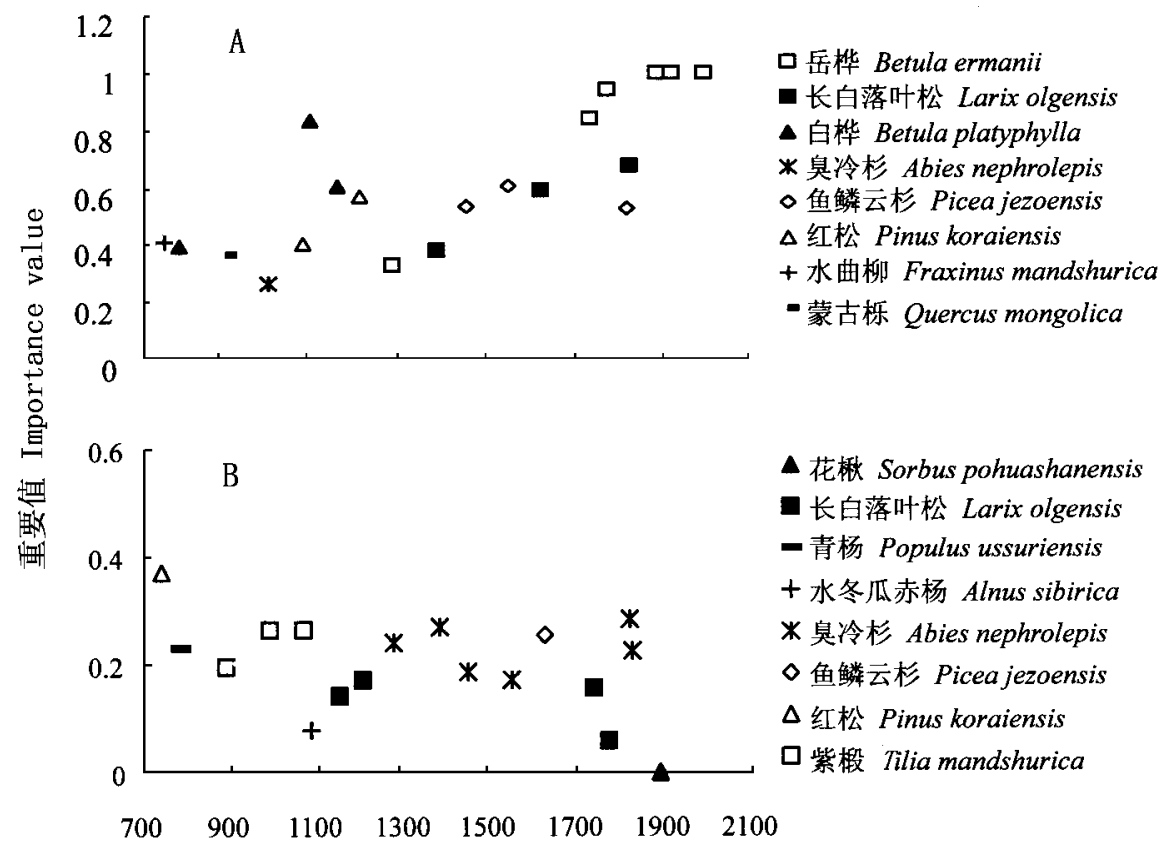

海拔 Altitude（m) 

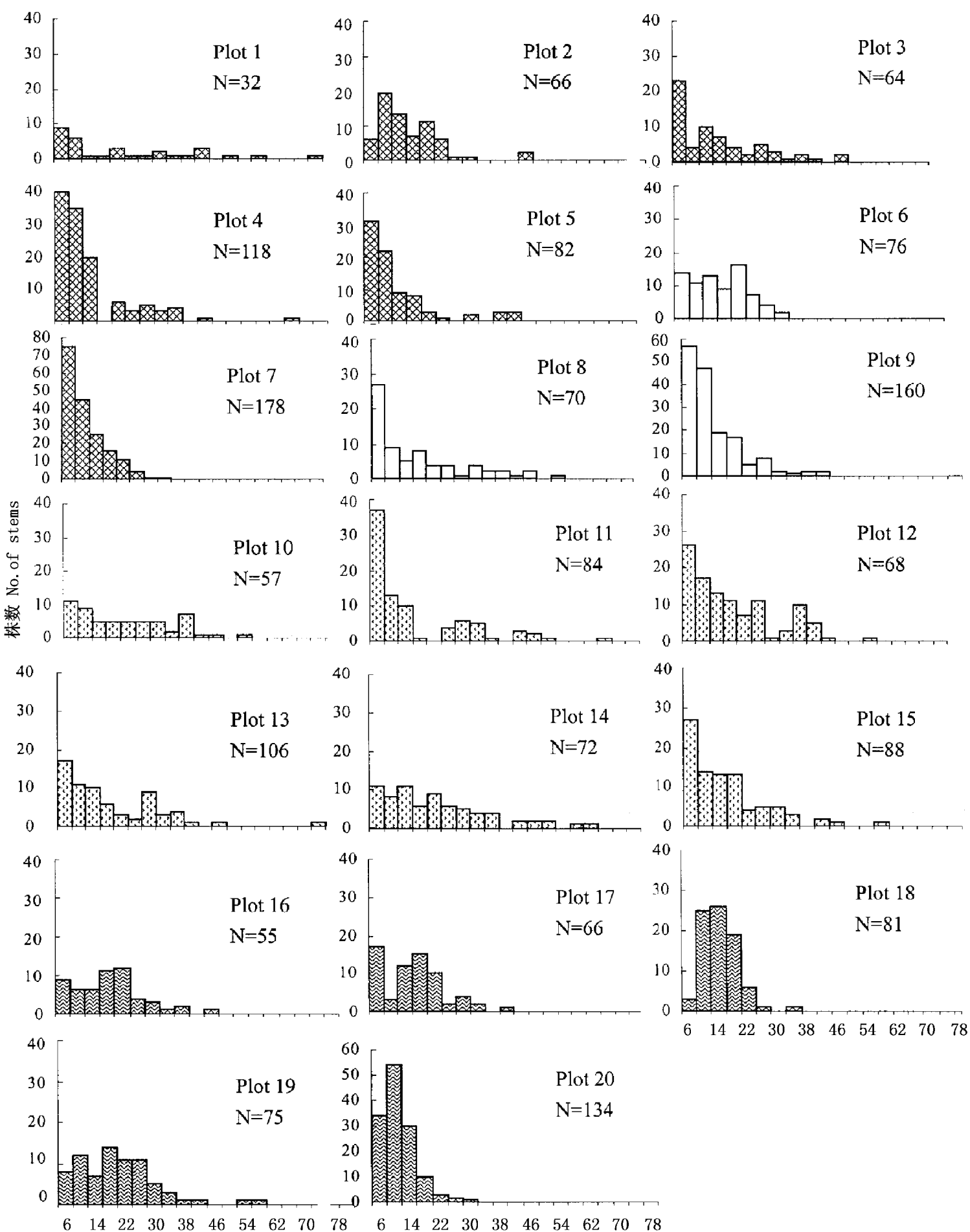

$\begin{array}{llllllllllllllllllll}6 & 14 & 22 & 30 & 38 & 46 & 54 & 62 & 70 & 78 & 6 & 14 & 22 & 30 & 38 & 46 & 54 & 62 & 70 & 78\end{array}$

径级中值 Median of DBH classes (cm)

回 红松针阔混交林 Mixed coniferous and broad-leaved forest community

$\square$ 红松针阔叶树种与云冷杉组成的过渡群落

Mixed coniferous and broad-leaved forest and sub-alpine coniferous forest community

园 云冷杉暗针叶林 Sub-alpine coniferous forest community

岳桦林 A1pine Birch forest community

图 4 乔木样方的径级频度分布

Fig. 4 Frequency distribution of DBH classes for tree plots of Mt. Changbai. 


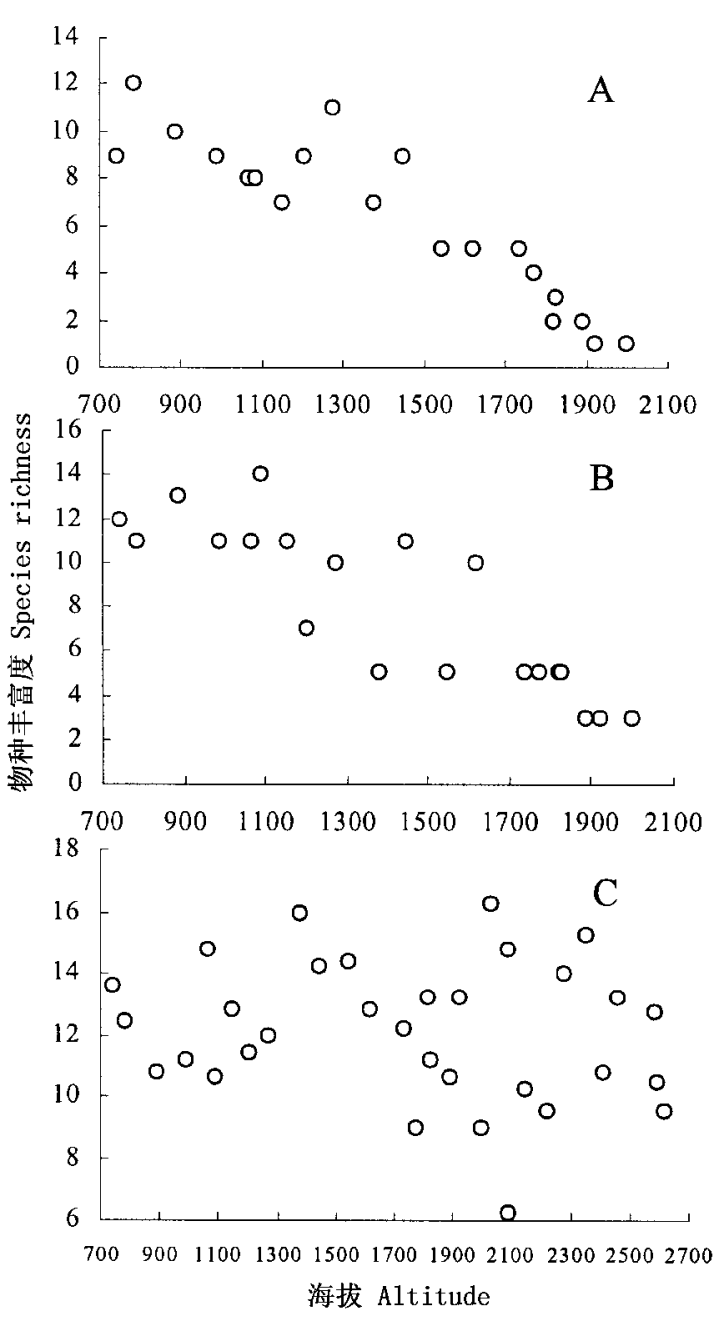

图 5 乔木层 $(\mathbf{A})$ 、灌木层 $(\mathbf{B})$ 和草本层 $(\mathbf{C})$ 物种丰富度随 海拔梯度的变化格局

Fig. 5 Patterns of species richness for (A) tree layer, (B) shrub layer and $(\mathrm{C})$ herb layer along an altitudinal gradient

\section{2 物种多样性的垂直变化格局}

\subsection{1 物种丰富度随海拔梯度的变化}

在 32 个样方中，共记录到乔木层树种 33 种, 灌 木层树种 46 种, 草本层植物 233 种。不同生活型的 植物的物种多样性随海拔梯度的变化格局不尽相 同。图 5 表明，乔木层树种丰富度随海拔增加总体 上呈线性下降趋势, 但在海拔 $1300 \mathrm{~m}$ 左右有一个不 大的峰值。参考前面 TWINSPAN 植物群落分类结 果可以发现, 该高度对应的植被类型为红松针阔混 交林与亚高山暗针叶林的过渡带, 表明过渡带具有 较高的物种多样性。

灌木层树种丰富度随海拔增加也基本呈下降趋
势,但在亚高山暗针叶林带内出现几个低谷值。暗 针叶林植被带以鱼鳞云杉、臭冷杉等针叶树种为主， 林内阴冷潮湿, 因而灌木和草本相对较少。另外, 在 海拔 $1150 \mathrm{~m}$ 处以白桦占优势的群落中，灌木层的物 种丰富度较大, 这可能与白轧群落内部结构较为稀 疏、光线较为充足有关。

木本植物物种多样性与海拔高度的负相关关 系，与郝占庆等 (2002) 对于该地区的研究结果是一 致的。这也是普遍存在于不同生态系统中的物种丰 富度随海拔梯度的一种变化格局 (Pausas \& Austin， 2001 ; Hamilton \& Perrott , 1981 ; Whittaker , 1956)。

草本层物种丰富度随海拔梯度没有明显的变化 趋势。可能是因为调查时间和取样面积的不同, 这 一结果与郝占庆等 (2002) 得出的长白山北坡草本 层物种丰富度随海拔升高而下降的结论不同。

\subsection{2 $\alpha$ 多样性沿海拔梯度的变化}

Shannon-Wiener 指数与样方中每个物种各个个 体的大小有关, 而 Pielou 指数即均匀度指数反映的 是样方中每个种的多度的均匀程度。从不同生活型 植物物种的 $\alpha$ 多样性随海拔梯度的变化格局 (图 6) 可以发现 : 乔木树种的 $\alpha$ 多样性随海拔的升高呈下 降趋势, Shannon-Wiener 指数从红松针阔混交林的 最高值 1.77 下降到暗针叶林的 0.23 直至高山岳桦 林的 0 (单一组成种) ; 在海拔 $1150 \mathrm{~m}$ 处的白桦群 落内出现一个低谷; 在红松针阔混交林 - 暗针叶林 及暗针叶林 - 高山岳桦林的过渡带分别出现小的峰 值。灌木层植物物种的 $\alpha$ 多样性 (Shannon-Wiener 指数) 也有随海拔升高而降低的负相关关系, 但是 变化趋势没有乔木层明显。草本层的 $\alpha$ 多样性沿 海拔梯度没有明显的变化趋势。这种 $\alpha$ 多样性的 变化格局与以往的大多数研究结果一致 (唐志尧 等 2004)。

无论是木本层还是草本层的 Pielou 均匀度指数 都没有在海拔梯度上表现出明显的变化规律。可能 是因为物种均匀度更多地受到群落自身特征的影 响,而对于环境梯度的变化不敏感（王国宏， 2002 )。比如在乔木层中, 海拔 $1065 \mathrm{~m}$ 处优势种比 较突出的红松针阔混交林内 Pielou 均匀度指数出现 较小值; 而在海拔 $1771 \mathrm{~m}$ 鱼鳞云杉、臭冷杉分布比 较均匀的暗针叶林带, 均匀度指数出现一个峰值。 上述分析表明, 在分析物种多样性沿海拔梯度的变 化格局时，区分生活型来考虑是有必要的。 

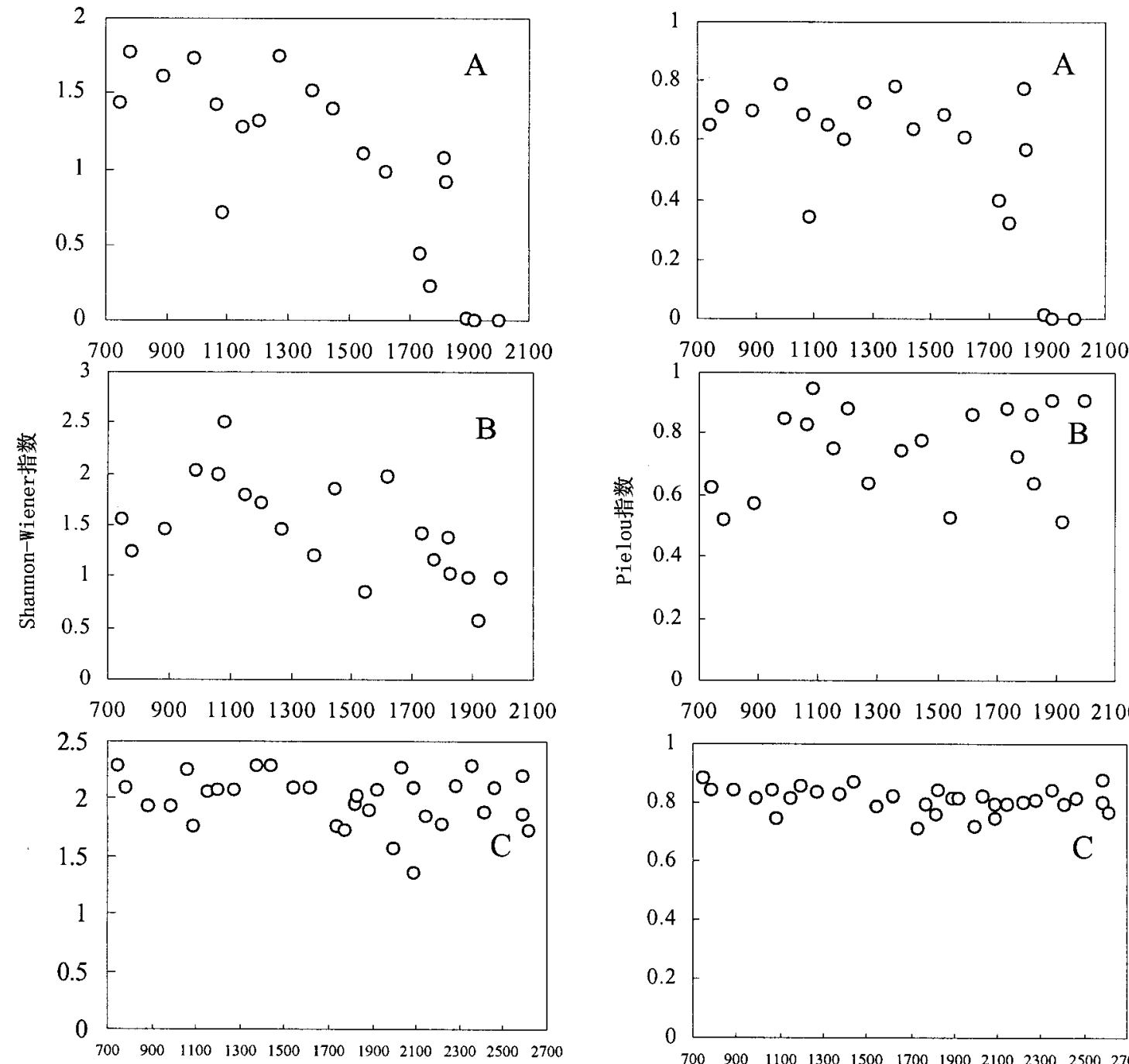

$\begin{array}{llllllll}700 & 900 & 1100 & 1300 & 1500 & 1700 & 1900 & 2100\end{array}$

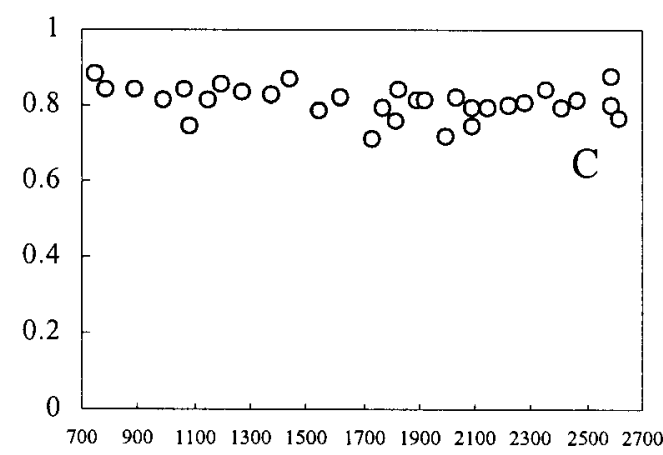

海拔 Altitude (m)

海拔 Altitude (II)

图 6 乔木层 $(\mathbf{A})$ 、灌木层 $(\mathbf{B})$ 和草本层 $(\mathbf{C}) \boldsymbol{\alpha}$ 多样性随海拔梯度的变化格局

Fig. 6 Patterns of $\alpha$ diversity for ( A) tree layer , (B) shrub layer, and ( C) herb layer along an altitudinal gradient

\subsection{3 $\boldsymbol{B}$ 多样性随海拔梯度的变化}

因为距离的大小会影响 $\beta$ 多样性的比较,因 此, 在研究长白山北坡 $\beta$ 多样性随海拔梯度的变化 格局时，尽量将相邻两个海拔间的垂直距离统一到 $100 \mathrm{~m}$ 左右。

图 7 的结果表明, 乔木层、灌木层和草本层的 $\beta$ 多样性 (Cody 指数) 随海拔的升高均呈下降趋势, 但是不同生活型的植物物种多样性变化细节不尽相 同。乔木层树种的 $\beta$ 多样性随海拔上升呈明显线 性下降, 但在海拔 $887-987 \mathrm{~m}$ 的红松针阔混交林植 被带内相邻群落的生境类型之间、1202-1272 m 红
松针阔混交林 - 亚高山暗针叶林的过渡带内及 $1619-1734 \mathrm{~m}$ 的亚高山暗针叶林植被带内相邻群 落类型间的 $\beta$ 多样性出现低谷, 表明在同一植被带 或过渡带内, 各群落的生境条件比较接近, 群落物种 组成比较相似。

灌木层 $\beta$ 多样性随海拔升高也呈明显的下降 趋势, 但在 $1085-1202 \mathrm{~m}$ 和 $1202-1272 \mathrm{~m}$ 海拔区 间出现两个低谷, 因为这三个海拔高度位于同一植 被过渡带, 即红松针阔混交林和亚高山暗针叶林过 渡带内, 群落生境条件差异很小。在 $1619-1734 \mathrm{~m}$ 和 $1734-1800 \mathrm{~m}$ 海拔区间同样出现两个低值，从样 

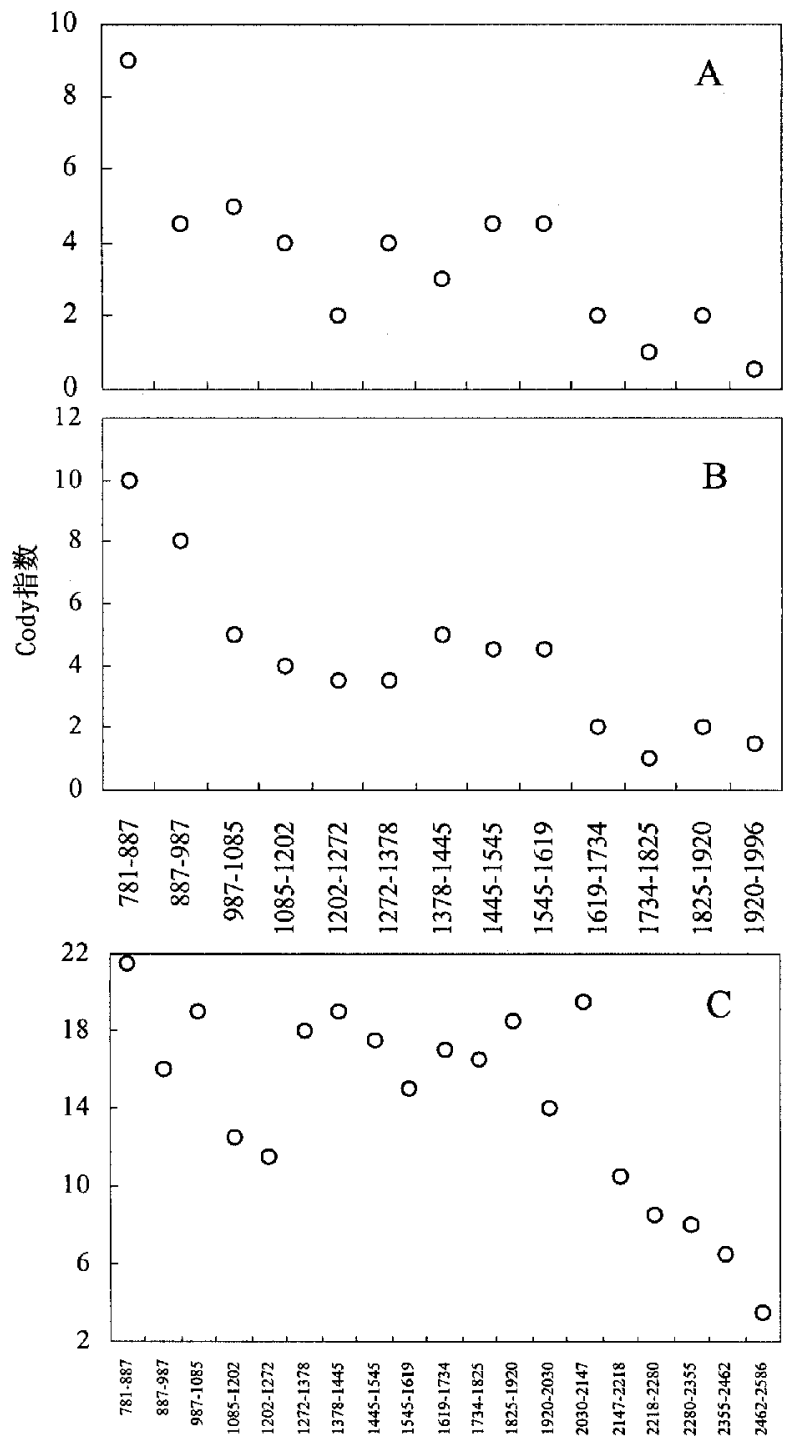
海拔段 Altitudinal band (II)

图 7 乔木层 $(\mathbf{A})$ 、灌木层 $(\mathbf{B})$ 和草本层 $(\mathbf{C}) \boldsymbol{\beta}$ 多样性随海 拔梯度的变化格局

Fig. 7 Patterns of $\beta$ diversity for (A) tree layer, (B) shrub layer, and $(\mathrm{C})$ herb layer along an altitudinal gradient

方资料和 TWINSPAN 群落分类结果不难发现，海拔 $1600-1800 \mathrm{~m}$ 的群落位于亚高山暗针叶林带内，林 内灌木层物种本来就少, 故而 $\beta$ 多样性较低。草木 层 $\beta$ 多样性随海拔上升也表现出一定的下降趋势， 但在 $1734-1825 \mathrm{~m}$ 海拔区间以下,变化规律不明 显。

与大部分的研究结果相似（王国宏，2002; Vazquez \& Givnish,1998)，长白山北坡无论是木本 层还是草本层植物物种的 $\beta$ 多样性均随海拔升高 而单调下降。可能是由于分布在低海拔地区的物种
具有较小的生态位，所以较小的生境梯度就能引起 较多的物种更替, 因而 $\beta$ 多样性较高。

\section{3 结语}

乔木层样方 TWINSPAN 分类结果将长白山北 坡植物分为 4 个群落类型。从低海拔到高海拔依次 为红松针阔混交林、红松针阔叶树种与云冷杉组成 的过渡群落、云冷杉暗针叶林和岳桦林。乔木层优 势种重要值的分布清楚地反映了长白山北坡植被垂 直带谱的优势成分。4 种森林群落树木个体的胸径 分布均呈现倒 J” 型, 表明这些森林类型的天然更 新状况良好。

植物物种多样性随海拔梯度的垂直变化研究表 明, 不同生活型植物的物种多样性随海拔梯度的变 化趋势不同。乔木层和灌木层的物种丰富度随海拔 升高呈下降趋势; 而草本层的物种丰富度随海拔梯 度的变化格局没有明显规律。乔木层和灌木层植物 的 $\alpha$ 多样性 (Shannon-Wiener 指数) 随海拔上升而 下降, 草本层的 $\alpha$ 多样性随海拔梯度没有明显的变 化规律。植物群落各层次的 Pielou 均匀度指数都没 有在海拔梯度上表现出明显的变化规律。乔木层、 灌木层和草本层植物的 $\beta$ 多样性 (Cody 指数) 均 随着海拔的升高而下降。

本研究分析了长白山北坡乔木层的群落类型、 组成和结构, 研究了植物物种多样性随海拔梯度的 垂直变化格局，通过分析不同群落的组成和结构，对 植物物种多样性的这种垂直变化格局进行了初步解 释, 并没有深入探讨产生这种变化格局的环境因素。 将这种植物多样性的垂直变化格局与相应的环境因 子进行相关分析进而解释其变化格局是今后要进一 步开展的工作。

致谢：参加野外调查工作的还有李晓文、陈阳、申松 兰等, 特此致谢。

\section{参考文献}

Austin, M. P. 1980. Searching for a model for use in vegetation analysis. Vegetatio, 42: $11-21$.

Austin, M. P., Pausas, J. G. and Nicholls, A. O. 1996. Patterns of tree species richness in relation to environment in southeastern New South Wales, Australia. Australian Journal of Ecology, 21: 154 - 164 
Austrheim, G. 2002. Plant diversity patterns in semi-natural grasslands along an elevational gradient in southern Norway. Plant Ecology, 161: 193 - 205.

Beals, E. W. 1969. Vegetation changes along altitudinal gradients. Science, 165: $981-985$.

Begon, M., Harper, J. L. and Townsend, C. R. 1996. Ecology: Individuals, Populations and Communities ( 2nd edn. ). Blackwell Science, Oxford.

Brown, J. H. 1988. Species Diversity. In: Myers, A. A. and Giller, P. S. ( eds.), Analytical Biogeography: An Integrated Approach to the Study of Animal and Plant Distribution. Chapman \& Hall, New York, 57 - 89.

Deng, H. B., Hao, Z. Q. and Wang, Q. L. 2001. The changes of co-possession of plant species between communities with altitudes on northern slope of Changbai Mountain. Journal of Forestry Research, 12 (2): 89 - 92.

Dolezal, J. and Srutek, M. 2002. Altitudinal changes in composition and structure of mountain-temperate vegetation: a case study from the Western Carpathians. Plant Ecology,

158: $201-221$.

Hamilton, A. C. and Perrott, R. A. 1981. A study of altitudinal zonation in the montane forest belt of Mt. Elgon, Kenya/Uganda. Vegetatio, 45: $107-125$.

Liu, Q. J. 1997. Structure and dynamics of the subalpine coniferous forest on Changbai Mountain, China. Plant Ecology,

132: $97-105$.

Magurran, A. E. 1988. Ecological Diversity and Its Measurement. Princeton University Press, Princeton.

McCoy, E. D. 1990. The distribution of insects along elevational gradients. Oikos, 58: $313-322$.

Odland, A. and Birks, H. J. B. 1999. The altitudinal gradient of vascular plant richness in Aurland, western Norway. Ecography, 22: 548 - 566.

Pausas, J. and Austin, M. P. 2001. Patterns of plant species richness in relation to different environments: an appraisal. Journal of Vegetation Science, 12: 153 - 166.

Pielou, E. C. 1977. Mathematical Ecology. Wiley, New York.

Rahbek, C. 1997. The relationship among area, elevation, and regional species richness in neotropical birds. American Naturalist, 149: 875 - 902.

Sru, tek M. and Lepš, J. 1994. Variation in structure of Larix olgensis stand along altitudinal gradient on Paektu-san, Changbai-Shan, North Korea. Arctic and Alpine Research,
26: $166-173$.

Vazquez, G. J. A. and Givnish, T. J. 1998. Altitudinal gradients in tropical forest composition, structure, and diversity in the Sierra de Manantlan. Journal of Ecology, 86: 999 1020 .

Whittaker, R. H. 1956. Vegetation of the Great Smoky Mountains. Ecological Monographs, 26: 1 - 80 .

Whittaker, R. H. 1967. Gradient analysis of vegetation. Biological Reviews, 42: 207 - 264.

Whittaker, R. H. 1975. Communities and Ecosystems. Macmillan Publisher, New York.

Hao, Z. Q. (郝占庆), Yu, D. Y. (于德永), Wu, G. (吴 刚), Deng, H. B. (邓红兵), Jiang, P. (姜萍) and Wang, Q. L. (王庆礼) . 2001. Analysis on $\beta$ diversity of plant communities on northern slope of Changbai Mountain. Acta Ecologica Sinica (生态学报), 21 (12)：20182022. (in Chinese)

Hao, Z. Q. (郝占庆), Yu, D. Y. (于德永), Yang, X. M . (杨晓明) and Ding, Z. H. (丁之惠). 2002. $\alpha$ diversity of communities and their variety along altitude gradient on northern slope of Changbai Mountain. Chinese Journal of Applied Ecology (应用生态学报), 13 (7): 785 - 789. (in Chinese)

Tang, Z. Y. (唐志尧) and Fang, J. Y. (方精云). 2004. A review on the elevational patterns of plant species diversity. Biodiversity Science (生物多样性), 12(1)：20-28.

Wang, G. H. (王国宏). 2002. Species diversity of plant communities along altitudinal gradient in the middle section of Qilian Mountains, Zhangye, Gansu, China. Biodiversity Science (生物多样性), 10 (1)：7-14. (in Chinese)

Wang, Z. (王战), Xu, Z. B. (徐振邦), Li, X. (李昕), Peng, D. S. (彭定山) and Tan, Z. X . (谭征详). 1980. The main forest types and their features of community structure in northern slope of Changbai Mountain. Research of Forest Ecosystem (森林生态系统研究)，1: 25 -42. (in Chinese)

Zhang, F. S. (张凤山), Chi, Z. W. (迟正文) and Li, X. Y. (李晓宴). 1980. Preliminary analysis on the climate of the Changbai mountain area. Research of Forest Ecosystem (森林生态系统研究), 1: 193 -214. (in Chinese)

Zhu, T. C. (祝廷成). 1999. Alpine Plants on the Changbai Massif of China (中国长白山高山植物). Science Press, Beijing, 37. (in Chinese) 